\title{
Contribution of Decision Support System in Enhancing Productivity and Profitability of the Firm
}

\author{
Tanuja Kaushik \\ GD Goenka University, Gurgaon \\ Monica Bhardwaj \\ Institute for International Management and Technology, Gurgaon
}

\begin{abstract}
The business paradigms are changing amidst changing business environment. There are newer technologies at disposal, rising customer awareness and their expectations from the need to attain efficiency and effectiveness in business processes for survival and competitive advantage. This paper provides insights on the significance of business decision making and present state of organizations that are striving to achieve optimal utilization of limited business resources. The paper highlights the nature of linear programming model and its importance in effective business decision making. The business impact of model is illustrated in the case using the linear programming model and transportation method through excel solver in computer manufacturing firms to help in deciding optimum quantity to produce within limited resources and how the computers manufactured can be distributed to market places at minimal cost. The paper elicits the effectiveness of the linear programming model to realize good decision making in business by meeting the business objectives through optimal utilization of resources. It concludes that model driven decision support system enhances the productivity and profitability of the firm in a constrained environment and is a highly effective model for solving business problems.
\end{abstract}

Keywords: Decision Support System, Linear Programming, Transportation, Decision Making, Resource Optimization.

\section{INTRODUCTION}

厂 $n$ this era of new technologies and growing competition it is essential that firms are focused on providing low cost and high quality products and services in order to survive and be successful. There is need for instant and accurate information, flexibility in operations and offerings and focus on agility. Today, the customer is well informed and demands a very high degree of variability. Decision-making is a very complex activity and in present scenario the constant need for optimal production plan required to minimize material cost, labour cost, and idle inventory and maximize the profits and growth by effective utilization of available resources creates the need of support system. Decision Support System (DSS) helps in providing a computational model driven approach to formulate the optimal production plan for the manufacturing industry with preset objectives and goals by proper and precise estimation of the requirements so that no excess or shortage of raw materials

Journal of Technology

Management for Growing Economies

Vol. 4 No. 2 Oct 2013 pp. $85-96$

\section{ChITKARA 司 UNIVERSITY}

(C)2013 by Chitkara University. All Rights Reserved. 
Kaushik, T.

Bhardwaj, M.

and huge transportation expenses etc are incurred. The best possible method of production, transportation etc. are deployed.

\section{DSS Description}

"DSS is model-based set of procedures for processing data and judgments to assist a manager in his decision making" (Little, 1970). DSS helps in reduction of production costs and improvement of productivity and sustainability as it helps in matching various available plans in manufacturing systems.

The use of DSS aids the decision making in the scenario of uncertainty with lack of proper information generating different optimal solutions based on the importance of each decision maker's opinion (Mahdi and Seyed, 2009). The application of Linear Programming and Transportation models is not only limited to computer manufacturing firms but can be applied across all industries. The use of model based interactive DSS (Opti link) in planning process aided planners in generating revenues by determining an optimal transportation. This optimal plan realized reduction in planning time to less than one and a half hours and also helped in maximizing total sales by delivering contracts at computed upper bound prices (Derigs and Friederichs, 2009).

DSS using Linear Programming provided a shift from empirical form of harvesting decisions to a modeled approach for scheduling of optimized sugarcane harvesting operations obtaining the maximum possible profit (Scarpari and Beauclair, 2010).

Deployment of Linear Programming model helped in identifying the appropriate optimal contract portfolio for energy trading by providing risk assessment, successfully identified risk situations and opportunities related to short-term prices in order to maximize the performance of the contracts portfolio (Teive et al., 2011).

DSS can be classified in various ways, based on the kind of use as the criterion. Power $(2001 ; 2002)$ has categorized DSS into five types. These are-

1. Communications-driven DSS

2. Data-driven DSS

3. Document driven DSS

4. Knowledge-driven DSS 
5. Model-driven DSS

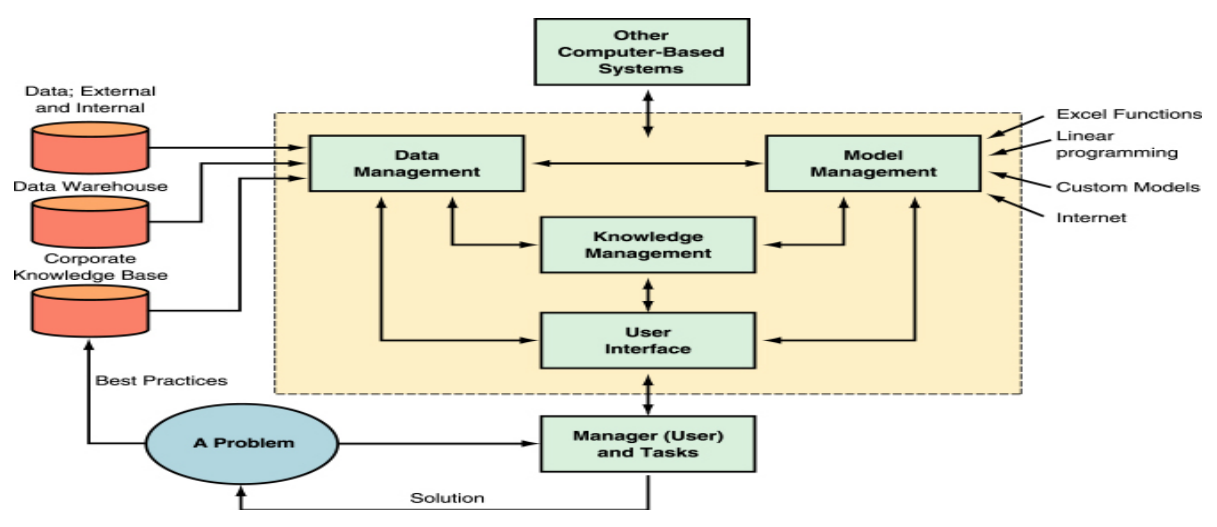

Contribution of

Decision

Support

Figure 1: (Source-Rainer et al., 2007)

Although there have been variety of approaches and different components given by authors for DSS, a generalized architecture is proposed by academicians and the industry practitioners that is made of six components as shown in Figure 1.

Data management subsystem: It stores data in databases, data warehouse, file systems etc. It can contain internal company data like company repository or external data like from internet. Data can also be from user's individual views, observations or experiences. The storage and management of data is done by software called the database management system (DBMS).

Model management subsystem: It deals with the representation of the data, facts or figures in a specified manner. It includes models from various areas viz., financial, statistical, simulation, management science models. Both qualitative and quantitative models are included and managed by it. Model base management system (MBMS) is the software used for model management. Examples can be optimization model for identifying optimum route, linear programming model.

Knowledge management subsystem: Knowledge management subsystem gives acumen to enhance the operations of the other DSS components. It can act as an independent subsystem or can support other subsystems. It provides expertise in solving complex problems. It creates a DSS that is intelligent. A good example is Data Mining.

User -Interface subsystem: This component of DSS facilitates use of DSS where the user communicates with the DSS.

The User: This component offers different usage patterns for different category of users like the manager, staff or the decision maker. 
Kaushik, T.

Bhardwaj, M.

\section{LITERATURE REVIEW}

DSS has displayed efficiency in different types of organizations with diverse needs by offering various computational models. With mixed integer linear programming model (MILP) in forest road upgrade planning there was minimization of the total cost of Transportation. Therefore, upgrading of forest road planning could be achieved. Thus, the case studies can be performed efficiently with respect to time required to acquire and organize data and to identify solutions as compared with earlier approaches. In addition, there was fine quality in the analysis and efficiency in the evaluation of results (Karlsson et al., 2006).

MILP resulted in improvement of the production scheduling process in a big chemical plant by developing better understanding of communication process and conflict between individual decision makers (Abreu et al., 2008).

Spatial decision support system (SDSS) along with binary integer linear programming model facilitated the land-use suitability analysis for choosing the best landscape reclamation strategy for open-pit coalmines. Out of various reclamation schemes, the optimal strategy intended for a long-term scale was chosen for maximizing the sustainability of the wide mining area (Pavloudakis et al., 2009).

Therefore, to aid decision-making and optimize results different types of DSS models used are-

System and Process Model: The system model demonstrates the model of the system under study. Process models show the processes that are going to be followed to carry out decision-making with respect to a system.

Deterministic and Stochastic: In deterministic models the output values are fixed for a given set of inputs, however in case of stochastic models there is always a level of uncertainty associated.

Static and dynamic: Static model shows values of system attributes in balanced situations. It is independent of time variations. Whereas, dynamic model shows results of changes in system attributes in time. It varies with time, has cause and effect relationship with time.

Linear and Non Linear: The linear or continuous models are those in which the numbers representing the system keep changing with time. The non-linear or discrete models occur are individual instances that occur at determined time and change the entire value of the system. The DSS model used in present study is Linear Programming model.

\section{Linear Programming (LP)}

LP optimizing methods and models play a vital role in diverse supply chain applications. In any business whether it be a manufacturing firm or firms involved in supply chain operations, several business activities compete

Journal of Technology Management for Growing Economies, Volume 4, Number 2, Oct 2013 
for resources like machine capacity, inventory of the finished product at a distribution center, raw materials, labour, etc. that are limited and quantities available in short supply. Some activities may use numerous resources in generating desired outputs. Hence, utilizing LP models resources needed to be allocated across the entire system can be analyzed and the usability and scarcity of resources can be generated to plan an optimal utilization.

\section{TRANSPORTATION}

Transportation refers to the movement of product from one place to another as it makes its way from the beginning of a supply chain until reaching in the hands of customer. Transportation plays a key role in every supply chain because products are rarely produced and consumed at the same location. Thus, transportation model is a special type of LP model where the objective is to minimize the cost of distributing a product from a number of sources or origins to a number of destinations. The origin of a transportation problem is the supply centre and the destination of a transportation problem is the demand centre. The unit transportation cost is the cost of transporting one unit of the product from an origin to a destination.

\section{Mathematical Problem Formulation}

(1) Identify the Decision Variables of interest to the decision maker and express them as $\mathrm{x}_{1}, \mathrm{x}_{2}, \mathrm{x}_{3} \ldots \ldots$ or $\mathrm{x}, \mathrm{y}, \mathrm{z} \ldots \ldots$

(2) Ascertain the Objective Function of the decision maker whether he wants to minimize or to maximize. The cost can be taken as the objective function in case of minimization problem or the profit can be taken as objective function in case of maximization problem per unit of each of the decision variables.

(3) Ascertain the constraints representing the maximum availability or minimum commitment or equality and represent them as less than or equal to $(<=)$ type inequality or greater than or equal to $(>=)$ type inequality or 'equal to' (=) type equality respectively.

(4) Put non-negativity restriction as under:

$\mathrm{x}_{1}>=0, \mathrm{x}_{2}>=0, \mathrm{x}_{3}>=0 \ldots \ldots$ (Non-negativity restriction)

(5) Formulate the LP problem as under:

Objective Function: Maximize (or Minimize)

$\mathrm{Z}=\mathrm{c}_{1} \mathrm{x}_{1}+\mathrm{c}_{2} \mathrm{x}_{2} \ldots \ldots \mathrm{c}_{\mathrm{n}} \mathrm{x}_{\mathrm{n}}$

Subject to constraints:

$$
a_{11} x_{1}+a_{12} x_{2} \ldots . . a_{1 n} x_{n}<=b_{1} \text { (Maximum availability) }
$$

Contribution of

Decision

Support 
Kaushik, T.

Bhardwaj, M. $\mathrm{a}_{21} \mathrm{x}_{1}+\mathrm{a}_{22} \mathrm{x}_{2} \ldots \ldots \mathrm{a}_{2 \mathrm{n}} \mathrm{x}_{\mathrm{n}}<=\mathrm{b}_{2}$ (Minimum commitment)

$a_{31} x_{1}+a_{32} x_{2} \ldots . . a_{3 n} x_{n}=b_{3}$ (Equality)

$\mathrm{a}_{\mathrm{m} 1} \mathrm{x}_{1}+\mathrm{a}_{\mathrm{m} 2} \mathrm{x}_{2} \ldots . . \mathrm{a}_{\mathrm{mn}} \mathrm{x}_{\mathrm{n}}<=($ or $>=) \mathrm{b}_{\mathrm{m}}$

$\mathrm{x}_{1}, \mathrm{x}_{2} \ldots . \mathrm{x}_{\mathrm{n}}>=0$ (Non-negativity restriction)

The decision variable (1) refers to the economic or physical quantities, which are competing with one another for sharing the given limited resources. The relationship among these variables must be linear under linear programming. The solution of the linear programming problem is the computed values of decision variables.

The objective function (2) of a linear programming problem is linear function of the decision variable expressing the objective of the decision maker. This can be either, maximization of profits or contribution, minimization of cost/time.

The constraint (3) indicates the limited resources, which are to be allocated among various decision variables. These resources may be production capacity, manpower, time, space or machinery. These must be capable of being expressed as linear equalities (i.e. $=$ ) or inequalities (i.e. $>=$ or $<=$ ) in terms of decision variables. Thus, constraints of a linear programming problem are linear equalities or inequalities arising out of practical limitations.

Non-negativity restriction (4) indicates that all decision variables must take on values equal to or greater than zero.

\section{CASE STUDY}

A simple test case is presented to explain how linear programming model can be effectively constructed to help computer-manufacturing firms in deciding how much quantity to produce optimally with the limited resources and how to distribute the computers to market places at minimal cost.

A production manager of Alpha computer company is considering a weekly resource allocation. XYZ sells 3 types of computers: the desktop computer, the laptop computer, and the workstation computer. The net profits of each desktop, laptop and workstation computer sold are Rs.350, Rs.470 and Rs.610 respectively.

This week $120 \mathrm{hrs}$ are available on the A-line test equipment where assembled desktop computer and laptop computer are tested, and $48 \mathrm{hrs}$ are available on the $\mathrm{C}$-line test equipment where assembled workstation computer are tested. The testing of each computer takes $1 \mathrm{hr}$.

In addition, production is constrained by the availability of 2000 labour hours for product assembly; each desktop, laptop and workstation computer requires 10, 15 and 20 labour hours respectively. There are other activities at Alpha that are involved in producing these computers, but testing and assem- 
bly are the ones consuming scarce resources.

Plant is located in Delhi. A company warehouse is located in Bangalore. Alpha sells its computers in the eight markets. The XYZ distribution manager needs to decide on a plan of meeting current week's demand for shipping desktop computers from its plant and its warehouse to various markets.

Alpha has 100 desktop computers on hand to be shipped from its plant and 45 desktop computers on hand to be shipped from its warehouse.

The table below shows the market demand along with the cost per unit to ship desktop computers from each source to each market. Here the transportation cost includes handling cost at the facilities, at the markets and trucking (mileage) costs.

Table 1: Market demand and Transportation cost data (Rs/unit)

\begin{tabular}{|l|c|c|c|c|c|c|c|l|l|}
\hline \multicolumn{10}{|c|}{ Transportation cost data (Rs/unit) } \\
\hline FROM/TO & MKT 1 & MKT 2 & MKT 3 & MKT 4 & MKT 5 & MKT 6 & MKT 7 & MKT 8 & SUPPLY \\
\hline PLANT & 14.00 & 24.00 & 21.00 & 20.00 & 21.50 & 19.00 & 17.00 & 30.00 & 100 \\
\hline WAREHOUSE & 24.00 & 15.00 & 28.00 & 20.00 & 18.50 & 19.50 & 24.00 & 28.00 & 45 \\
\hline DEMAND & 22 & 14 & 18 & 17 & 15 & 13 & 15 & 20 & \\
\hline
\end{tabular}

Problem description

i. To help production manager in allocating these resources to maximize profits for the next week

ii. To help distribution manager minimize the total transportation cost of shipping desktop computer from the sources to the markets.

\section{Solution}

i. To help production manager in allocating these resources to maximize profits for the next week the LP model can be formulated as follows:

LP model for the above problem can be formulated as follows:

Let,

$\mathrm{x}=$ No. of desktop computers to be assembled, tested, and sold during the week

$\mathrm{y}=$ No. of laptop computers to be assembled, tested, and sold during the week $\mathrm{z}=$ No. of workstation computers to be assembled, tested, and sold during the week

$\mathrm{Z}=$ Objective Function

$$
Z=350 x+470 y+610 z
$$

Subject to constraints:

$$
\mathrm{x}+\mathrm{y}<=120 \quad \text { (A-line test capacity) }
$$


Kaushik, T.

Bhardwaj, M.

$$
\mathrm{z}<=48
$$$$
10 \mathrm{x}+15 \mathrm{y}+20 \mathrm{z}<=2000
$$

(C-line test capacity)

(Labour Availability)

Non-Negative Restriction

$$
\mathrm{x}, \mathrm{y} \& \mathrm{z}>=0
$$

Now excel solver will be used as a powerful tool for data analysis and as a predictive tool for decision making and forecasting. Excel solver comes free with MS-Office. We need to go to excel options and just do the add-ins excel solver for use.

\section{Solvers and Results}
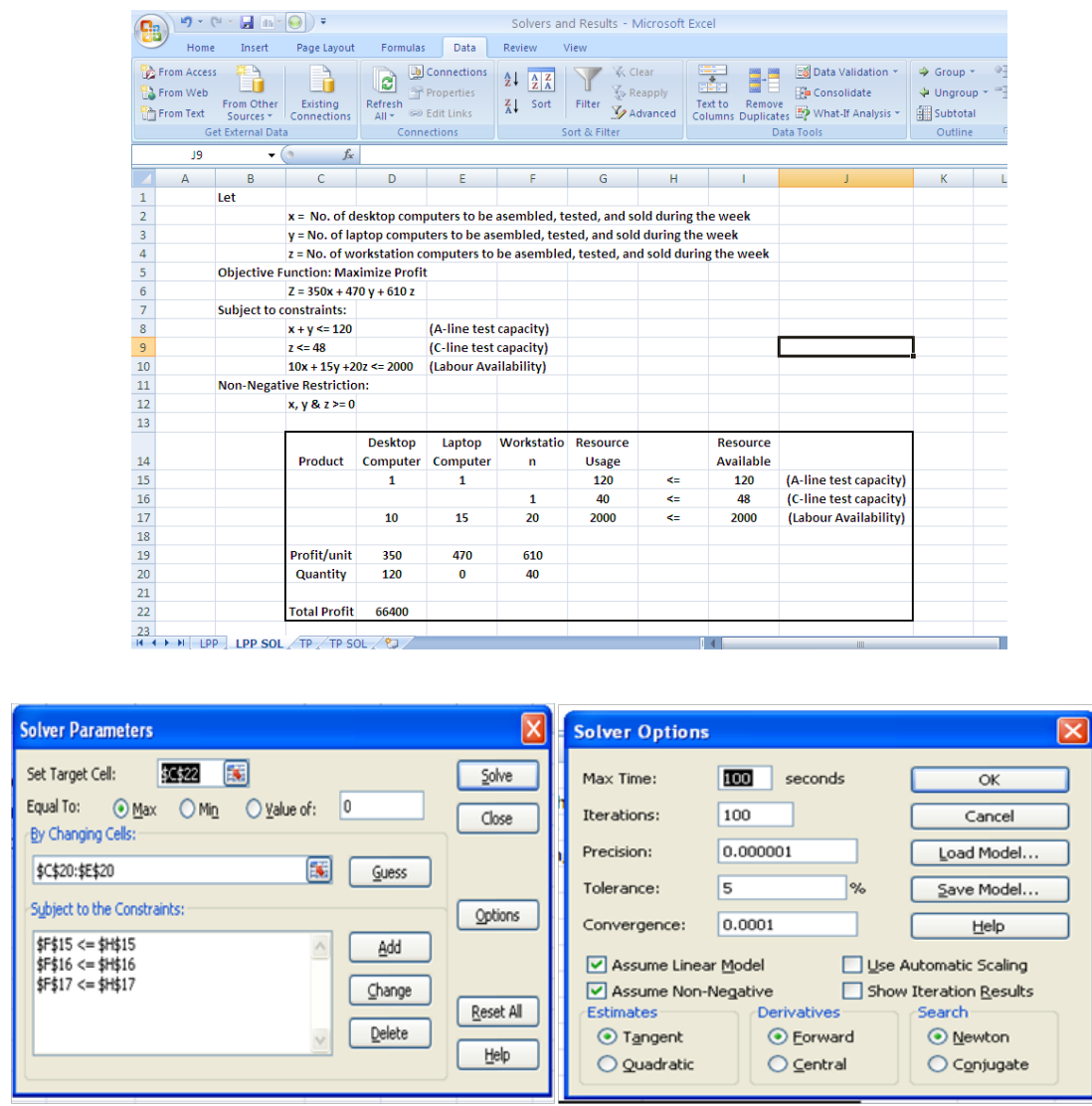

Figure 2 : Maximum Profit by allocating scarce resources

Figure 2 depicts that under the given constraint of number of hours of test equipment and labour availability and non-negative constraint, the maximum profit is Rs 66400. To get this profit number of desktop computers to be 
produced and sold is 120 and number of workstation computers to be produced and sold is 40. It is advisable that we do not produce any laptop computer.

It is also to be noted that we have utilized 120 complete hours that were available on A-line test equipment where as only 40 hours out of 48 hours available were utilized on C-line test equipment. As far as labour hours are concerned, 2000 complete labour hours were utilized that were available in order to get maximum profit.

i. To help distribution manager minimize the total transportation cost of shipping desktop computers from the sources to the markets.

LP model for the above transportation problem can be formulated as follows: Objective Function: Minimize Transportation Cost

$$
\begin{aligned}
& Z=14 X_{11}+24 X_{12}+21 X_{13}+20 X_{14}+21.50 X_{15}+19 X_{16}+17 X_{17}+30 X_{18} \\
& +24 X_{21}+15 X_{22}+28 X_{23}+20 X_{24}+18.50 X_{25}+19.50 X_{26}+24 X_{27}+28 X_{28}
\end{aligned}
$$

Subject to constraints:

$$
\begin{aligned}
& X_{11}+X_{12}+X_{13}+X_{14}+X_{15}+X_{16}+X_{17}+X_{18}<=100 \\
& X_{21}+X_{22}+X_{23}+X_{24}+X_{25}+X_{26}+X_{27}+X_{28}<=45 \\
& X_{11}+X_{21}>=22 \\
& X_{12}+X_{22}>=14 \\
& X_{13}+X_{23}>=18 \\
& X_{14}+X_{24}>=17 \\
& X_{15}+X_{25}>=15 \\
& X_{16}+X_{26}>=13 \\
& X_{17}+X_{27}>=15 \\
& X_{18}+X_{28}>=20
\end{aligned}
$$

Non-Negative Restriction:

$$
\mathrm{X}_{\mathrm{ij}}>=0 \quad \text { for } \mathrm{i}=1,2 \text { and } \mathrm{j}=1,2,3,4,5,6,7,8
$$

Now excel solver will be used as a tool for data analysis and as a predictive tool for decision making and forecasting. 
Kaushik, T.

Bhardwaj, M.
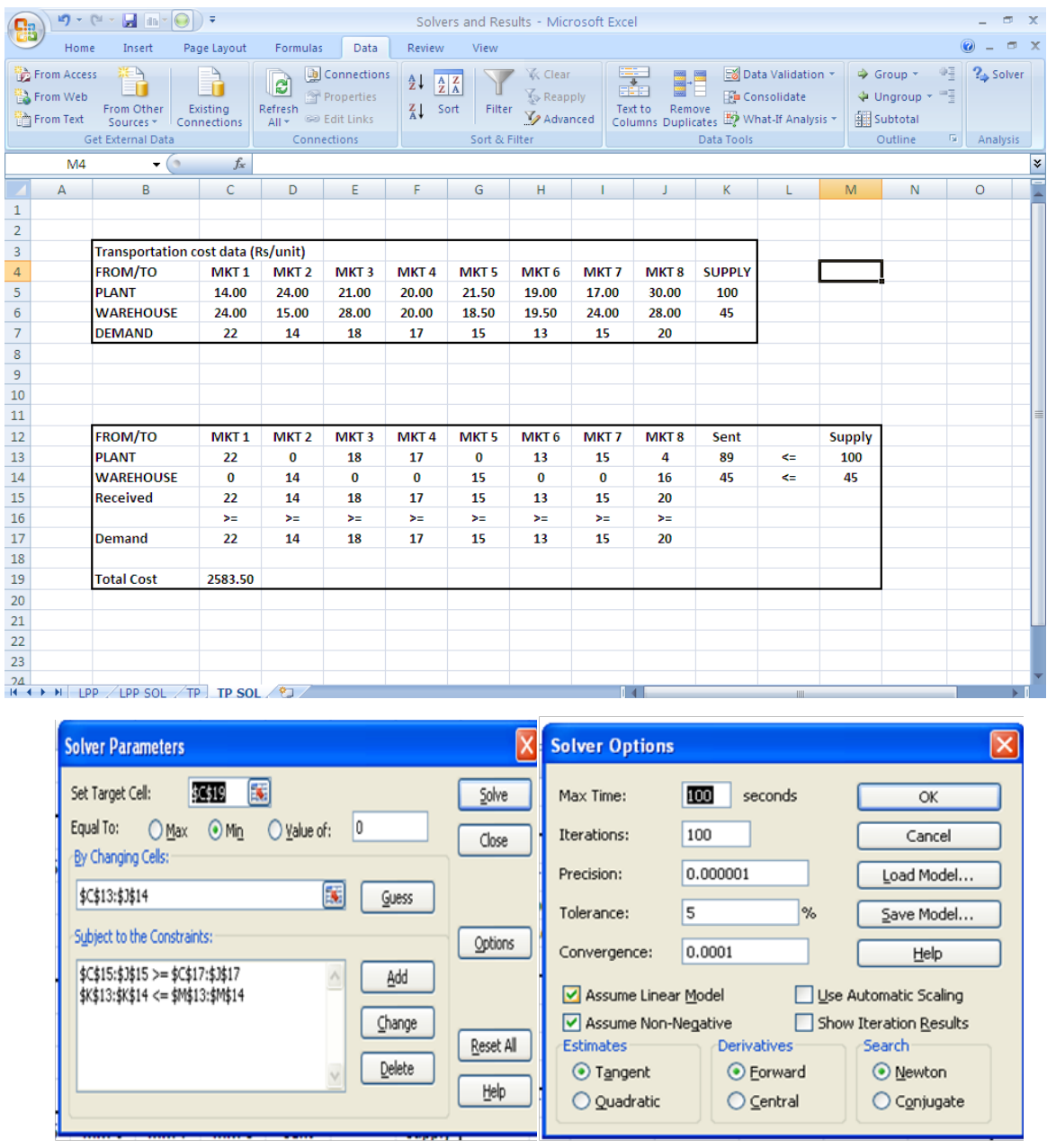

Figure 3: Minimum cost by distributing product to match demand and supply

To transport desktop computers from plant and warehouse to eight different markets the minimum cost incurred is Rs. 2583.50, which is depicted in Figure 3. Since, the total supply of desktop computers is 145 (plant and warehouse) and the total demand of desktop computer from eight different markets is 134, so 11 desktop computers will not be distributed.

The plant had 100 desktop computers but only 89 were distributed to meet the demand of the markets whereas warehouse had 45 desktop computers and all were distributed to meet the demand of the markets as depicted in Figure 3. Therefore, 11 desktop computers, which were not distributed, are those, which are remaining in the plant. 


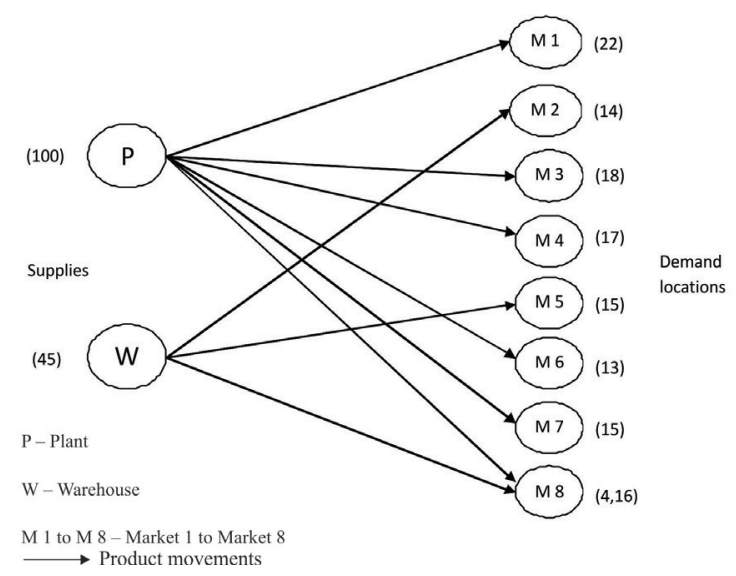

Contribution of

Decision

Support

Figure 4: Transportation of product from destination to sources

Figure 4 clearly states that the total supply of desktop computers at the plant is 100 and total supply of desktop computers at the warehouse is 45 . The desktop computers demand for Market 1 is 22, Market 3 is 18, Market 4 is 17, Market 6 is 13 and Market 7 is 15 is met by plant. On the other hand desktop computers demand for Market 2 is 14 and Market 5 is 15 is met by the warehouse. It is interesting to note that desktop computers demand for Market 8 is 20 and is jointly met by plant and warehouse with 4 and 16 units respectively.

\section{CONCLUSIONS}

The problem of computer manufacturing company has been easily resolved by using linear programming and transportation method through excel solver. Since most of the problems faced by manufacturing organizations are of similar nature, so linear programming technique ensures possible solutions are generated and out of which the optimal solutions are selected. It can also be used for re-evaluation of basic plan for changing conditions. If the condition changes in between the plan it can be accurately determined with the help of linear programming to adjust the remainder of the plan for best results. For example, in case of computer manufacturing company if test equipment goes out of order or a group of labour go on strike resulting in reduction of number of hours available on test equipment and labour availability. In such a situation, linear programming technique can be effectively used in finding the best and optimal solution under the given changed condition.

The effectiveness of model is restricted not only to the manufacturing industry but has its application in hotel, agriculture, refineries, railways etc. For example, the selection of routes and allocation of aircrafts to various chosen 
Kaushik, T. Bhardwaj, M.

routes are done by airlines using linear programming model. In addition, the location of Rajendra Bridge over the Ganges linking South Bihar and North Bihar in Mokama has been achieved only with the help of this model. Thus, the paper concludes that model driven DSS enhances the productivity and profitability of the firm in a constrained environment.

\section{REFERENCES}

Abreu, C.F., May, J.H., Spangler, W. E. and Vargas, L.G. (2008) 'Conflict Identification And Reconciliation in a Collaborative Manufacturing Scheduling Task', International Journal of Information Technology \& Decision Making, 7:1, pp. 147-174. http://dx.doi. org/10.1142/S0219622008002855.

Derigs, U. and Friederichs, S. (2009) 'On the application of a transportation model for revenue optimization in waste management- a case study', Central European Journal of Operations Research, 17:1, pp. 81-93. http://dx.doi.org/10.1007/s10100-008-0058-y.

Karlsson, J., Ronnqvist, M. and Frisk, M (2006) 'Road Opt: A decision support system for road upgrading in forestry', Scandinavian Journal of Forest Research, 21:7, pp. 5-15. http:// dx.doi.org/10.1080/14004080500487102.

Little, J. D. C. (1970) 'Models and Managers: The Concept of a Decision Calculus', Management Science, 16:8, pp. B466-485.

Mahdi, B. and Seyed, H. (2009) 'A fuzzy group decision support system for multifacility location problems', International Journal of Advanced Manufacturing Technology, 42:5/6, pp. 533. http://dx.doi.org/10.1007/s00170-008-1621-3.

Pavloudakis, F., Galetakis, M. and Roumpos, C. (2009) 'A spatial decision support system for the optimal environmental reclamation of open-pit coal mines in Greece', International Journal of Mining, Reclamation and Environment, 23:4, pp. 291-303. http://dx.doi. org/10.1080/17480930902731935.

Power, D. J.(2001) 'Supporting Decision-Makers: An Expanded Framework.', In Harriger, A. (eds), e-Proceedings, Informing Science Conference, June 19-22, Krakow, Poland, pp. 431-436.

Power, D. J. (2002) Decision support systems: concepts and resources for managers, Westport CT, Greenwood/Quorum.

Rainer, R. K., Turban, E. and Potter, R. E. (2007) 'Introduction to Information System' (1st edition), New Jersey, John Wiley \& Sons.

Scarpari, M.S. and Beauclair, E. G. F., (2010) 'Optimized Agricultural planning of sugarcane using linear programming', Revista Investigacion Operacional, 31:2, pp. 126-132.

Teive, R. C. G., Lange, T., Arfux, G. A. B., Queiroz, A. K. and Rosa, L. F. S. C. (2011) 'A Decision support system for Energy trading and Portfolio Optimization', Journal of Energy and Power Engineering, 5, pp. 349-355. http://dx.doi.org/10.1109/EEM.2010.5558692.

Tanuja Kaushik, Associate Professor, G D Goenka University, Gurgaon.

Monica Bhardwaj, Assistant Professor, Institute for International Management and Technology, Gurgaon. Email: monica29rose@gmail.com.

Journal of Technology Management for Growing Economies, Volume 4, Number 2, Oct 2013 